\title{
Training and Development Competencies: A Comparative Study of Their Importance and Demonstration
}

\author{
Dr. M. Srimannarayana \\ Professor, Human Resource Management \\ XLRI \\ Jamshedpur, India
}

\author{
Received: March 14, 2019 Accepted: May 25, 2019 Published: July 1, 2019 \\ doi:10.5296/jmr.v11i3.14505 URL: https://doi.org/10.5296/jmr.v11i3.14505
}

\begin{abstract}
The study aims at assessing the importance of training and development competencies of training and development professionals and their demonstration of the same while performing their roles and responsibilities, as well as to identify the gaps between the importance and the demonstration. The study adopted the conceptual framework from the American Society of Training and Development (ASTD) model, which was created by Arneson, Ruthwell and Naughton (2013). 248 training and development professionals were the sample of the study for the rating of importance and another 248 line professionals, who were familiar with the training and development professionals' functioning, were the sample of the study for the demonstration rating. Based on the data collected from the sampled professionals and its analysis, the study concludes that overall, technology literacy, performance improvement, evaluating learning impact, managing learning programs, coaching, knowledge management and change management are the areas of competencies in which training and development professionals need to enhance their proficiency.
\end{abstract}

Keywords: Training and Development Competencies, Training Professionals, Line Professionals, India 


\section{Introduction}

Advances in technology and internet capability, advances in software applications, growing adoption of mobile devices for learning, a culture of connectivity and information sharing, increased ability to use and collect 'big data', shifting demographics in the workforce, increasing globalization, and economic volatility and uncertainty are the key trends driving change in competencies required among training and development professionals (Arneson et aal., 2013). The training and development profession in India is also getting affected by these trends in the context of considering this country as an emerging talent powerhouse, predicted to be among the world's five largest economies and viewed by investors, businesses, and tertiary education providers as a land of opportunities (Budhwar, \& Varma, 2011; Rao and Varghese, 2009; Pio, 2007). India has made a significant progress with respect to increased training budgets, application of technology in training, strategic linkage of training, rapid changes in training delivery, and systematic needs assessment (Srimannarayana, 2006). Indian training and development practitioners need to demonstrate appropriate competencies to contribute to the firm's financial performance through their training and development endeavours. Against this background, this study is undertaken to make a comparative analysis of training and development competencies required by training and development professionals and the extent of the demonstration of these competencies, while performing their roles and responsibilities.

\section{Conceptual Framework}

McClelland (1973) who is credited with coining the term competency, defined it as a characteristic that underlies successful performance. Over the years, many writers and leaders in the filed defined and redefined the term competency and its related terms. It is causally related to criterion-referenced effective and/or superior performance in a job or a situation (Spencer and Spencer, 1993). Competencies indicate ways of behaving, or thinking, generalizing across situations, and enduring for a reasonably long period of time (Guion, 1991). Coming to competencies of training and development professionals, over the years, American Society for Training and Development (ASTD) sponsored studies to identify the competencies that keep evolving over time, based on the changes taking place in the business environment. Pinto and Walker (1978) conducted a study of training and development competencies. This is the first published effort sponsored by ASTD. It aimed at defining the basic skills, knowledge, understanding and other attributes required for training and development professionals for effective performance. The study found that analyzing and diagnosing needs, determining appropriate training approaches, designing and developing programs, developing material resources, managing internal and external resources, developing and counseling individuals, preparing job or performance-related training, conducting classroom training, developing groups and organization, conducting research on training, managing working relationships, managing training function, and managing professional self-development are the major areas of training and development professionals.

Later, McLagan and McCullough (1983) created a human resource "wheel", a definition of 
training and development, a list of 34 future forces expected to affect the training field, 102 critical outputs for the field, four role clusters with a matrix of 15 roles with 31 competencies of training and development professionals. The study of McLagan (1989) expanded this concept going beyond training to include career development and organizational development, naming the field as human resource development (HRD). It is the integrated use of training and development, organizational development, career development to improve individual, group, and organizational effectiveness. This framework created 35 competencies and 11 roles for HRD professionals.

Going beyond traditional training and HRD, Rothwell (1996) developed a model for human performance improvement (HPI). HPI is a systematic process of discovering and analyzing important human performance gaps, planning for future improvements, designing and developing cost-effective, ethically justifiable interventions to close the gaps, implementing the interventions, and evaluating the financial and nonfinancial results. This model identified 15 core and 38 supporting competencies of HPI that are required to perform four roles such as: analyst, intervention specialist, change manager, and evaluator. Piskurich and Sanders (1998) developed a model for learning technologies focusing on instructional methods. This model examined the roles, competencies, and outputs that HRD professionals need to implement learning technologies within their organizations.

One year later, Rothwell, Sanders and Soper (1999) reexamined competencies required for the success in the field of workplace learning and performance (WLP). This study defined WLP as the integrated use of learning and other interventions for improving individual and organizational performance. It developed models for workplace learning and performance, which consisted of roles such as manager, analyst, intervention selector, intervention designer and developer, intervention implementer, change leader, and evaluator. Further, the study identified 52 competencies that are classified into six groups such as analytical competencies, technical competencies, leadership competencies, business competencies, interpersonal competencies, and technological competencies.

Taking into consideration business trends that are shaping up the training and development profession, five years later, Bernthal et al. (2004) reexamined the competency model and re-conceptualized it. This model included three layers, namely, foundational competencies, areas of expertise, and roles. The foundational competencies for WLP professionals were classified into three groups such as interpersonal competencies, business/management competencies and personal competencies. These competencies anchor the competency model. Achieving job success would be difficult for WLP professionals without some level of expertise in the majority of these foundational competencies. The second tier of the model covers specific areas of expertise such as designing learning, improving human performance, delivering training, measuring and evaluating, facilitating organisational change, managing the learning function, coaching, managing organizational knowledge, and career planning and talent management. These are positioned above foundational competencies because they direct and supplement the foundational competencies through special skills and knowledge. All the areas of expertise rely on specialized technologies to leverage and support them. This model placed four WLP roles, namely project manager, professional specialist, business 
partner, and learning strategist, above the areas of expertise, occupying peak of the model because WLP profession requires a certain combination of competencies and areas of expertise to perform the roles effectively.

Again, after nine years, ASTD revisited the competency model and modified 2004 model keeping in view the trends and drivers that are shaping the training and development profession. As presented in Figure 1, the new ASTD competency model created by Arneson et al (2013) identified six foundational competencies such as business skills, global mindset, industry knowledge, interpersonal skills, personal skills, and technology literacy. These are the bedrock upon which, training and development professionals have to build 10 specific areas of expertise such as change management, coaching, evaluating learning impact, instructional design, integrated talent management, knowledge management, learning technologies, managing learning programs, performance improvement, and training delivery. The foundational competencies are generic in nature. They are required across many professions, whereas the AOEs are unique and specific to training and development profession only.

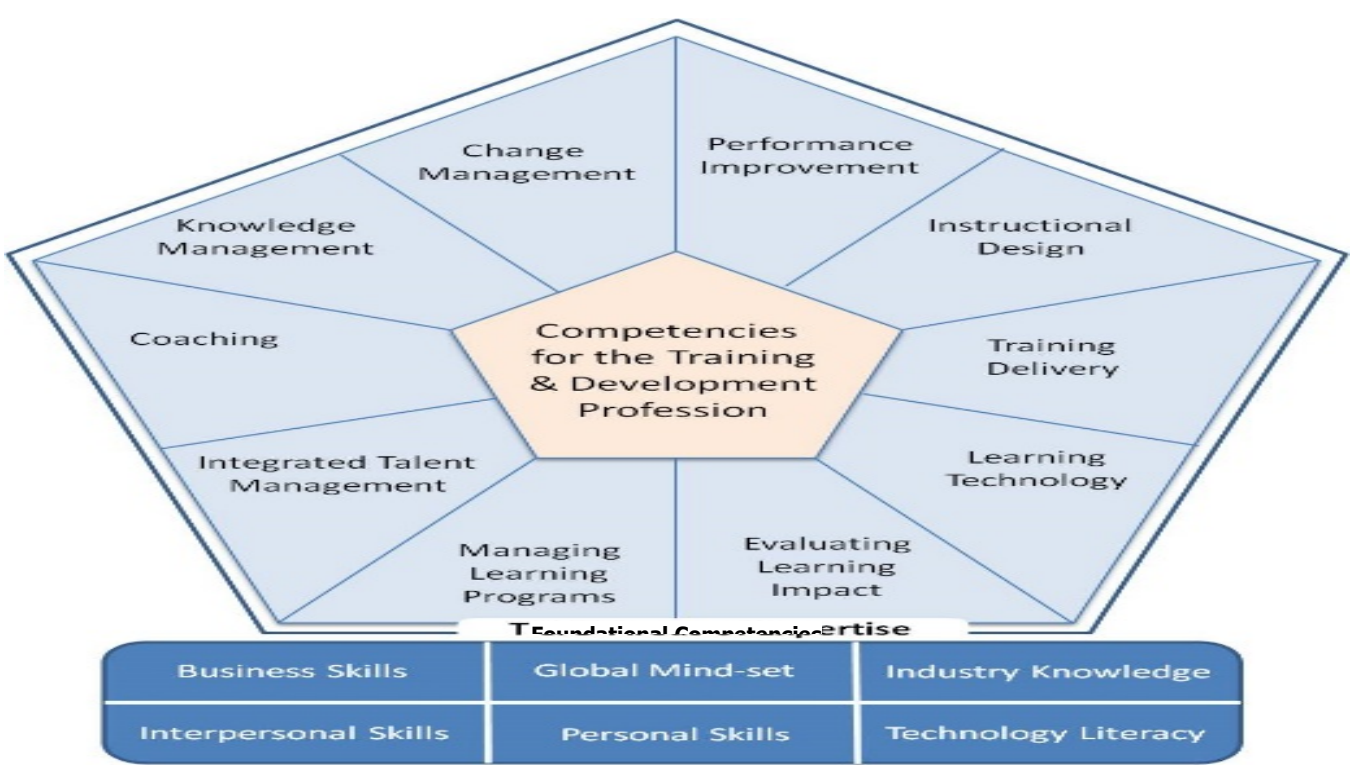

Source: Arneson, et al. (2013), ASTD Competency Study: The Training and Development Profession Redefined, Alexandria, VA: ASTD.

Figure 1. ASTD Competency Model (2013)

\subsection{Foundational Competencies}

According to the ASTD Competency Study (2013) business skills, global mind-set, industry knowledge, interpersonal skills, personal skills, and technology literacy are the foundational competencies. Business skills include analysing client needs and proposing appropriate learning solutions, applying business skills to build and document the business case for investing in learning solutions, driving results after setting well defined goals relating to learning solutions, planning and implementing assignments in a timely manner to ensure that learning and development goals are achieved, thinking strategically in creating learning 
and development strategies that are in alignment with business goals, and applying innovation by using new resources, methods, tools, or content to advance learning and development. Global mind-set is defined as appreciating and leveraging the capabilities, insights and ideas of all individuals, working effectively with individuals from different generations, who have diverse styles, motivations, abilities and background and working effectively across boarders and cultures. Industry knowledge refers to scanning and assesses information on current and emerging trends in training and development industry, and also developing and maintaining knowledge of other industries, as appropriate. Interpersonal skills include building trust, communicating effectively, influencing stakeholders, networking and partnering, and emotional intelligence. Personal skills are classified into demonstrating adaptability and modeling personal development. Technology literacy is defined as demonstrating an awareness with existing, new, and emerging technologies and identifying opportunities to leverage technology in order to accomplish learning tasks and achieve business goals.

\subsection{Areas of Expertise}

The ASTD competency study (2013) identified 10 areas of expertise for training and development professionals. A brief description of these areas of expertise is as follows:

1. Performance Improvement: It is applying a systematic process of discovering and analysing performance gaps, planning for future improvements in performance, and designing and developing solutions to close performance gaps.

2. Instructional Design: It is designing and developing informal and formal learning solutions to meet organizational needs, and selecting the most appropriate strategy to maximize learning experience and impact.

3. Training Delivery: It is delivering informal and formal learning solutions in a manner that engages the learner and produces desired outcomes, managing and responding to learner needs and ensuring that learning is made available in effective platforms and delivered in a timely and effective manner.

4. Learning Technologies: It is identification, selection, and application of a variety of learning technologies, adapting learning technologies, matching the appropriate technology to specific learning opportunity.

5. Evaluating Learning Impact: It is gathering, organising, and analysing data regarding learning impact and using learning metrics and analytics.

6. Managing Learning Programs: It is providing leadership to execute the organization's strategy, and planning, monitoring, and adjusting training and development activities.

7. Integrated Talent Management: It is building an organization's culture, engagement, capability, and capacity through the implementation, integrating of talent acquisition, development, retention and deployment processes, and ensuring these processes are aligned to organizational goals. 
8. Coaching: It is using an interactive process to help individuals develop rapidly and produce results, improving others' ability to set goals, take actions, make better decisions, and make full use of their natural strengths.

9. Knowledge Management: It is capturing, distributing, and archiving intellectual capital in a way that encourages knowledge sharing and collaboration in the organization.

10. Change Management: Applies structured approaches to shift individual, teams and organizations from a current state to a desired state.

\section{The Methodology}

The present research aimed at exploring answers to the following questions:

1. To what extent are the training and development competencies identified by ASTD competency model (2013) important for training and development professionals from their viewpoint in India?

2. To what extent do training and development professionals demonstrate these competencies from the viewpoint of line professionals who are familiar with the functioning of the training and development professionals?

3. What are the gaps between the importance of the competencies and their demonstration by training and development professionals? and,

4. Are there any differences in the importance and the demonstration of the competencies between the manufacturing, service and the IT sectors?

Two questionnaires were designed for this study covering the competencies identified by ASTD competency model (2013). The first questionnaire was aimed at eliciting data from training and development professionals to find out the extent of importance of training and development competencies. This was administered among training and development professionals working in different types of organizations with a request to answer the items on a five-point scale, one being 'unnecessary' and five being 'essential ' for them. The second one was administered on line professionals who are familiar with the functioning of the training and development professionals who responded to the first questionnaire in the same organization. These line professionals were requested to assess the extent of demonstration of the competencies by the training and development professionals while discharging their roles and responsibilities. They were requested to answer the items on a five-point scale, one being 'not at all demonstrated' by the training and development professionals and five being 'always almost demonstrated'.

Altogether 712 filled-in questionnaires were received from the executives working in 108 organizations in India. After reviewing all the questionnaires, 496 (248 pairs of the questionnaires representing training and development professionals and their line executives) questionnaires received from the respondents, working in 94 organizations were considered for analysis. The data collected was subjected to reliability test. Overall, Cronbach's alpha value was calculated as 0.960 . Descriptive statistics such as frequency distributions, percentages 
were used for the analysis of demographic information of the respondents. Mean scores, standard deviations, and t-tests and one-way ANOVA were employed for analyzing data relating to training and development competencies.

As presented in Table 1, 44. 76\% of the sampled respondents represented the manufacturing sector, which included organizations related to agro products, automobiles, electronics, engineering, fast moving consumer products, oil and gas, pharmaceuticals, and steel. 39.52\% of them worked for the service sector such as banking, consulting, education, e-commerce, facilities management, financial services, food services, health care, hospitality, media, and retail services, self-help groups, and telecommunication services. $15.73 \%$ belonged to the information technology sector. The respondents were asked to state the approximate percentage of coverage of training and development competencies in the items of the questionnaire. Taking into consideration all the respondents, together, on an average, the questionnaire covered approximately $81.93 \%$ of training and development competencies.

Table 1. The Sample Distribution

\begin{tabular}{|l|c|c|c|c|c|c|}
\hline \multirow{2}{*}{$\begin{array}{l}\text { Nature of } \\
\text { business }\end{array}$} & \multicolumn{2}{|c|}{$\begin{array}{c}\text { Line } \\
\text { Professionals }\end{array}$} & \multicolumn{2}{|c|}{ Training Professionals } & \multicolumn{2}{c|}{ Total } \\
\hline & Frequency & $\%$ & Frequency & $\%$ & Frequency & $\%$ \\
\hline Manufacturing & 111 & 44.76 & 111 & 44.76 & 222 & 44.76 \\
\hline Service & 98 & 39.52 & 98 & 39.52 & 196 & 39.52 \\
\hline IT & 39 & 15.73 & 39 & 15.73 & 78 & 15.73 \\
\hline Total & 248 & 100.00 & 248 & 100.00 & 496 & 100.00 \\
\hline
\end{tabular}

\section{Findings}

\subsection{Manufacturing Sector - Foundational Competencies}

Table 2 presents the data relating to training and development competencies pertaining to the manufacturing sector. The mean scores of importance rating of the foundational competencies ranged from 3.57 to 4.04 as given by the respondent training and development professionals. The means scores of their demonstration as rated by the respondent line professionals ranged from 3.13 to 3.40 . According to the training and development professionals, the top three important foundational competencies for the success in their profession are: business skills, personal skills and interpersonal skills. They rated these three skills as 'very important' for their success. The respondent line professionals perceived that the training and development professionals in their respective organizations demonstrated these three competencies relatively better, but not to the extent of required. The mean scores indicated that these are the three areas, in which more gap was identified between the importance and the demonstration of these competencies. However, the results of one-way ANOVA test conducted to assess the gaps between the foundational competencies required and demonstrated in the manufacturing sector revealed a significant gap in the competency areas of business skills only. Therefore, training and development professionals have to bridge the gap between the required and demonstrated business skills by showing their understanding of the business of their organizations, strategies, goals, and finances and make 


\section{Al Macrothink}

use of this understanding for aligning the learning interventions with business.

\subsection{Manufacturing Sector - Areas of Expertise}

With respect to areas of expertise, the respondent training and development professionals viewed that training delivery, talent management, instructional design, managing learning programs, and performance management are 'very important' areas of expertise in the order of importance. However, the respondent line professionals could find a huge gap in the demonstration of these competencies, particularly, in the areas of training delivery, instructional design, and performance improvement. According to them, training and development professionals could demonstrate relatively better in the areas of managing learning programs, coaching and talent management. However, the results of one-way ANOVA test conducted to assess the differences between the importance and the demonstration, a significant difference is found in the areas of learning technology, evaluating learning impact and change management. It means that the line professionals expect that the training and development professionals should show their enhanced competency in making use of technology in designing, delivering and evaluating training and development programs. They have to identify, select, and apply a variety of learning technologies in their training and development activities. Evaluating learning impact is another area of expertise, in which a significant difference was identified between the importance and the demonstration of the competencies. Training and development professionals are expected to master the techniques, tools and methodologies to assess the effectiveness of training and development programs and measure their impact as expected by line professionals. Change management is another area in which a significant gap is identified between the required and the demonstrated levels. Training and development professionals are expected to apply structured approaches of change management so that the employees and the organization will be benefited. 
Table 2. One-way ANOVA Test: The Importance and the Demonstration Ratings of the Manufacturing Sector

\begin{tabular}{|c|c|c|c|c|c|}
\hline & Learning and development competencies & $\begin{array}{l}\text { Importance } \\
\text { Rating }\end{array}$ & $\begin{array}{l}\text { Demonstration } \\
\text { Rating }\end{array}$ & f-Statistic & Sig. \\
\hline & Foundational & & & & \\
\hline 1 & Business Skills & 4.0374 & 3.3755 & 3.651 & $0.04^{*}$ \\
\hline 2 & Global Mind-set & 3.7991 & 3.2369 & 1.197 & 0.35 \\
\hline 3 & Industry Knowledge & 3.5721 & 3.1261 & 2.716 & 0.06 \\
\hline 4 & Interpersonal Skills & 3.9986 & 3.3471 & 1.875 & 0.22 \\
\hline 5 & Personal Skills & 4.0342 & 3.3982 & 1.705 & 0.39 \\
\hline \multirow[t]{2}{*}{6} & Technology Literacy & 3.859 & 3.2613 & 1.609 & 0.22 \\
\hline & Areas of Expertise & & & & \\
\hline 7 & Performance Improvement & 4.0586 & 3.3829 & 1.963 & 0.18 \\
\hline 8 & Instructional Design & 4.1081 & 3.3874 & 0.305 & 0.83 \\
\hline 9 & Training Delivery & 4.2252 & 3.455 & 0.501 & 0.60 \\
\hline 10 & Learning Technology & 3.7748 & 3.2252 & 3.274 & $0.05^{*}$ \\
\hline 11 & Evaluating Learning Impact & 3.7703 & 3.1712 & 3.242 & $0.03 *$ \\
\hline 12 & Managing Learning Programs & 4.0676 & 3.518 & 0.831 & 0.75 \\
\hline 13 & Integrated Talent Management & 4.1532 & 3.509 & 0.662 & 0.76 \\
\hline 14 & Coaching & 3.9099 & 3.5135 & 1.37 & 0.24 \\
\hline 15 & Knowledge Management & 3.8468 & 3.2072 & 1.77 & 0.49 \\
\hline 16 & Change Management & 3.6396 & 3.045 & 6.181 & $0.00 *$ \\
\hline
\end{tabular}

\subsection{Service Sector - Foundational Competencies}

Table 3 depicts the data relating to training and development competencies in the service sector. The mean scores of the importance rating of the foundational competencies ranged from 3.81 to 4.18 as viewed by the respondent training and development professionals. The means scores of their demonstration as rated by the respondent line professionals ranged from 3.21 to 3.50 . The respondent training and development professionals of the service sector considered three foundational competencies, namely business skills, personal skills and interpersonal skills as 'very important'. The order of demonstration of the top three foundational competencies seemed to be a little different, which placed personal skills in the first position, followed by interpersonal skills and business skills. The means scores showed gaps between the importance and demonstration of all foundational competences. It is significant to note that the mean difference in the business skills between the importance and the demonstration seemed to be higher in the service sector, followed by global mind-set and interpersonal skills. However, the results of one-way ANOVA test conducted to assess the gaps between the importance and the demonstration in the service sector revealed a significant gap in the competency areas of business skills only. 


\subsection{Service Sector - Areas of Expertise}

The respondent training and development professionals in the service sector considered performance improvement, instructional design, training delivery and integrated talent management, and coaching as 'very important' areas of expertise in the order of importance as per the mean scores. However the order of demonstration of training and development professionals as rated by the respondent line professionals is managing learning programs, training delivery, instructional design, integrated talent management and performance improvement. Based on the mean scores, it may be stated that there is a gap between the importance and the demonstration in the areas of change management, performance improvement, evaluating learning impact, coaching and talent management. However, the results of one-way ANOVA test identified significant differences between the importance and the demonstration in the areas of learning technology, evaluating learning impact and change management. It is significant to note that these gaps are consistent with the gaps identified in the manufacturing sector.

Table 3. One-way ANOVA Test: The Importance and the Demonstration Ratings of the Service Sector

\begin{tabular}{|r|l|r|r|r|r|}
\hline & $\begin{array}{l}\text { Learning and development } \\
\text { competencies }\end{array}$ & \multicolumn{2}{l|}{$\begin{array}{l}\text { Importance } \\
\text { Rating }\end{array}$} & Remonstration \\
& Foundational & & & Sig. \\
\hline 1 & Business Skills & 4.1771 & 3.4643 & .833 & .027 \\
\hline 2 & Global Mind-set & 3.9284 & 3.2822 & 1.407 & .304 \\
\hline 3 & Industry Knowledge & 3.8061 & 3.2092 & .690 & .068 \\
\hline 4 & Interpersonal Skills & 4.1142 & 3.4716 & 1.312 & .156 \\
\hline 5 & Personal Skills & 4.1327 & 3.4959 & .689 & .184 \\
\hline 6 & Technology Literacy & 4.0036 & 3.3879 & 2.049 & .202 \\
\hline & Areas of Expertise & & & & \\
\hline 7 & Performance Improvement & 4.2143 & 3.4592 & 2.362 & .143 \\
\hline 8 & Instructional Design & 4.1582 & 3.5357 & 1.482 & .737 \\
\hline 9 & Training Delivery & 4.1429 & 3.5663 & .844 & .607 \\
\hline 10 & Learning Technology & 3.9490 & 3.3980 & 2.575 & .040 \\
\hline 11 & Evaluating Learning Impact & 4.0102 & 3.3061 & 1.038 & .041 \\
\hline 12 & Managing Learning Programs & 4.0051 & 3.6684 & 2.164 & .437 \\
\hline 13 & Integrated Talent Management & 4.0918 & 3.4694 & .296 & .517 \\
\hline 14 & Coaching & 4.0816 & 3.4388 & .471 & .256 \\
\hline 15 & Knowledge Management & 3.9796 & 3.3878 & 2.050 & .173 \\
\hline 16 & Change Management & 4.0306 & 3.2551 & 1.207 & .002 \\
\hline$* . T h e$ & & & \\
\hline
\end{tabular}

\subsection{IT Sector - Foundational Competencies}

Table 4 shows the data relating to training and development competencies in the IT sector. The mean scores of the importance rating of foundational competencies ranged from 3.73 to 


\section{Macrothink}

Journal of Management Research

ISSN 1941-899X

2019, Vol. 11, No. 3

4.01 as perceived by the respondent training and development professionals. The means scores of the demonstration as rated by the respondent line professionals ranged from 3.29 to 3.52. With respect to the demonstration of foundational competences, the respondent line professionals of IT sector felt that their training and development professionals could demonstrate better their technology literacy skills, personal skills and global mind-set better than other foundational competencies such as business skills and interpersonal skills. The mean differences between the importance rating and the demonstration rating is relatively higher in business skills and interpersonal skills. However, the results of one-way ANOVA test results did not reflect any statistically significant gap between the importance and demonstration ratings in the foundational competencies.

\subsection{IT Sector - Areas of Expertise}

Training delivery, knowledge management, instructional design, learning technology and performance are 'very important' areas of expertise in the order of importance as per the mean scores given by the respondent training and development professionals of the IT sector. However, the order of demonstration as rated by the respondent line professionals is: coaching, training delivery, instructional design, knowledge management and learning technology. Based on the mean scores, it may be stated that there is a gap between the importance and the demonstration in the areas of performance improvement, training delivery, knowledge management, integrated talent management and learning technology. It is interesting to note that with respect to the areas of expertise, like the manufacturing and the service sector, IT sector also showed a statistically significant gap between the importance and the demonstration in the areas of learning technology, evaluating learning impact and change management. 
Table 4. One-way ANOVA Test: The Importance and the Demonstration Ratings of the IT Sector

\begin{tabular}{|c|c|c|c|c|c|}
\hline & $\begin{array}{l}\text { Learning and development } \\
\text { competencies }\end{array}$ & $\begin{array}{l}\text { Importance } \\
\text { Rating }\end{array}$ & $\begin{array}{l}\text { Demonstration } \\
\text { Rating }\end{array}$ & $\begin{array}{c}\text { f-Statisti } \\
\text { c }\end{array}$ & Sig. \\
\hline & Foundational & & & & \\
\hline 1 & Business Skills & 4.0144 & 3.4182 & .07909 & 0.10 \\
\hline 2 & Global Mind-set & 3.7774 & 3.4521 & .12573 & 0.98 \\
\hline 3 & Industry Knowledge & 3.7308 & 3.2949 & 2.716 & 0.06 \\
\hline 4 & Interpersonal Skills & 3.9649 & 3.3674 & 1.875 & 0.22 \\
\hline 5 & Personal Skills & 3.9590 & 3.4667 & 1.705 & 0.39 \\
\hline \multirow[t]{2}{*}{6} & Technology Literacy & 4.0000 & 3.5213 & 1.609 & 0.22 \\
\hline & Areas of Expertise & & & & \\
\hline 7 & Performance Improvement & 4.0385 & 3.1667 & 1.963 & 0.18 \\
\hline 8 & Instructional Design & 4.0769 & 3.5513 & .305 & 0.83 \\
\hline 9 & Training Delivery & 4.2179 & 3.5769 & .501 & 0.60 \\
\hline 10 & Learning Technology & 4.0769 & 3.4872 & 3.274 & $0.05^{*}$ \\
\hline 11 & Evaluating Learning Impact & 3.8974 & 3.3590 & 3.242 & $0.03 *$ \\
\hline 12 & Managing Learning Program & 3.9231 & 3.3974 & .831 & 0.75 \\
\hline 13 & Integrated Talent Management & 4.0256 & 3.4103 & .662 & 0.76 \\
\hline 14 & Coaching & 3.9487 & 3.5897 & 1.370 & 0.24 \\
\hline 15 & Knowledge Management & 4.1282 & 3.5128 & 1.770 & 0.49 \\
\hline 16 & Change Management & 3.6923 & 3.2051 & 6.181 & $0.00 *$ \\
\hline
\end{tabular}

\subsection{Comparative Analysis}

The mean differences and the results of one-way ANNOVA are presented in Table 5. A look at the overall results pertaining to the manufacturing, service and the IT sectors indicate that the importance level of training and development competencies seems to be relatively higher in the service sector when compared to the manufacturing and IT sectors. With regard to the demonstration of the competencies, it seems that training and development professionals in the service and the IT sectors could demonstrate the competencies better than their counterparts in the manufacturing sector. The difference between the importance level and demonstration level of competencies seems to be higher in the service sector when compared to the manufacturing and IT sector. It is significant to note that the overall mean scores pertaining to demonstration of training and development competencies are found to be the same in the service and IT sector. However, when it comes to the gap between the importance and the demonstration, relatively more gap is found in the service sector. However, one-way ANOVA test results do not find any significant variations between these three sectors with respect to the importance and the demonstration of training and development competencies. 


\section{I Macrothink}

Table 5. Comparison of the Manufacturing, Service and the IT sectors: One - Way ANOVA Test Results

\begin{tabular}{|c|c|c|r|r|}
\hline $\begin{array}{c}\text { Nature of } \\
\text { Business }\end{array}$ & Importance & Demonstration & $\begin{array}{c}\text { Mean } \\
\text { Difference }\end{array}$ & F-statistic \\
\hline Manufacturing & 3.93 & 3.32 & 0.61 & 0.18605 \\
\hline Service & 4.05 & 3.42 & 0.63 & 0.19845 \\
\hline IT/ITES & 3.97 & 3.42 & 0.54 & 0.15125 \\
\hline \multicolumn{6}{|l|}{ Overall } & 3.98 & 3.39 & 0.59 & 0.17405 \\
\hline *The mean difference is significant at the 0.05 level. \\
\hline
\end{tabular}

\subsection{Overall Analysis}

Overall, the mean score of importance is calculated as 3.98 on a five-point scale indicating that training and development competencies considered in this study are very important for training and development professionals to perform their roles and responsibilities effectively. The overall mean for demonstration of the competencies was calculated as 3.39 indicating a gap of 0.61 between the importance and the demonstration. An independent sample t-test based on Levene's test for variance was conducted to find out the gaps between the importance and the demonstration of training and development competencies. Overall, it could be seen from Table 6, that there are differences in the mean scores in each competency ranging from 0.46 to 0.74 . As per the mean score differences, a relatively bigger gap is found in performance management, business skills, training delivery, instructional design, change management, interpersonal skills, evaluating learning impact, integrated talent management, and coaching . However, the results of the test of variance indicated that there is a significant difference between the importance and the demonstration of the competencies in the areas of technology literacy, performance improvement, evaluating learning impact, managing learning programs, coaching, knowledge management, and change management. It means that training and development professionals could not demonstrate their competencies in these areas as expected by the line professionals. 
Table 6. Independent Samples Test for competencies required and Demonstrated

\begin{tabular}{|c|c|c|c|c|c|}
\hline \multicolumn{6}{|c|}{ Levene's Test for Equality of Variances } \\
\hline \multicolumn{6}{|c|}{ Learning and development } \\
\hline $\mathrm{SN}$ & competencies & $\mathrm{F}$ & Sig. & $\mathrm{t}$ & Mean Difference \\
\hline & Foundational & & & & \\
\hline 1 & Business Skills & 3.256 & .072 & 16.239 & 0.67 \\
\hline 2 & Global Mind-set & .082 & .774 & 9.088 & 0.56 \\
\hline 3 & Industry Knowledge & .541 & .462 & 7.226 & 0.50 \\
\hline 4 & Interpersonal Skills & 2.609 & .107 & 13.207 & 0.64 \\
\hline 5 & Personal Skills & 2.196 & .139 & 11.864 & 0.61 \\
\hline \multirow[t]{2}{*}{6} & Technology Literacy & 7.088 & .008 & 9.595 & 0.59 \\
\hline & Areas of Expertise & & & & \\
\hline 7 & Performance Improvement & 6.576 & .011 & 12.189 & 0.74 \\
\hline 8 & Instructional Design & .914 & .340 & 11.062 & 0.65 \\
\hline 9 & Training Delivery & .518 & .472 & 11.438 & 0.67 \\
\hline 10 & Learning Technology & 1.138 & .287 & 8.714 & 0.56 \\
\hline 11 & Evaluating Learning Impact & 11.422 & .001 & 9.172 & 0.63 \\
\hline 12 & Managing Learning Programs & 10.848 & .001 & 7.505 & 0.46 \\
\hline 13 & Integrated Talent Management & 1.097 & .295 & 10.586 & 0.63 \\
\hline 14 & Coaching & 17.629 & .000 & 6.689 & 0.49 \\
\hline 15 & Knowledge Management & 7.613 & .006 & 7.877 & 0.62 \\
\hline 16 & Change Management & 4.663 & .031 & 7.789 & 0.65 \\
\hline
\end{tabular}

\section{Conclusion and Suggestions}

The analysis presented above leads to the conclusion that there is a significant gap between the importance and the demonstration of training and development competencies. Overall, the specific competency areas in which a gap is identified include technology literacy, performance improvement, evaluating learning impact, managing learning programs, coaching, knowledge management and change management. It is interesting to note that, comparatively speaking, there are variations in mean scores, but no significant variations are found between the manufacturing, service and the IT sectors in the importance and the demonstration of training and development competencies. It is interesting to note that there is a commonality of training and development competencies across the sectors of employment in India in their importance and the demonstration. Overall, it may be concluded that the training and development professionals did not meet the expectations of line managers in the above-mentioned areas of the competencies. The action plan that is required for training and development professionals to meet the expectations of the line professionals may be as follows:

Training and development professional have to understand, learn and demonstrate their skills in the areas of existing and emerging technologies that affect training and development. They 
have to identify opportunities to get benefit of technology in order to achieve success in their training and development activities that would help their organizations to achieve their business goals. Performance improvement is another area that needs to be improved. For an effective and efficient demonstration of this competency, the training and development professionals have to understand, learn and demonstrate the knowledge and skills of performance analysis, identification of performance gaps, root causes of the gaps, recommend cost-effective solutions to address the root causes, and integrate performance improvement with the business goals of the organization. They have to be skilled enough in communicating the performance expectations without in any way hurting the employees.

The line professionals expect effective leadership in managing learning programs. Training and development leaders need to understand their business models, organizational strategies, drivers, competitors of their organizations, and demonstrate their understanding of business in creating a vision of how training and development function can improve the performance of business in the context of its business scenario. They have to develop long-range training and development strategy to implement the vision and convert the strategy into training and development programs and execute them, balancing interests of the organization and the employees. Having executed them, training and development professionals have to learn and demonstrate their knowledge, skills and abilities in assessing the learning impact. This would be possible when the training and development professionals understand and learn different models of evaluations, learning analytics, analysis and data interpretation skills.

Coaching skills is another area of development for training and development professionals. Line professionals expect training and development professionals to enhance their coaching and mentoring systems so that employees can make use of these interactive processes for their development and thereby contribute to organizations by way of doing a better job. If this has to be done effectively, the training and development professionals have to learn and demonstrate coaching competencies, such as creating coaching programs, active listening, communicating effectively, and facilitating impactful learning in an interactive process. Managing organizational knowledge is also a concern for the line managers. They want the training and development professionals to put some systems in place to capture and distribute knowledge in a way that encourages knowledge sharing and collaboration in the organization. For an effective performance of this responsibility, the training and development professionals need to master the concepts and philosophy of knowledge management, adult learning theory, information architecture, database management and demonstrate their knowledge and skills in creating a knowledge management strategy and policy for their organizations and its execution. The line professionals expect that the training and development professionals demonstrate their change management skills effectively. To address this area, the training and development professionals need to master the change management theory, models, systems thinking, and demonstrate their knowledge and skills in facilitating organizational change. They have to apply structured approaches to shift individual, teams and organizations from a current state to a desired state. Thus, training and development professionals must continually update their knowledge, skills and abilities to adopt to the changing business realities and model personal and professional development to 
other managers in their organizations. Only then, organizations benefit immensely from the demonstration of training and development competencies, which in turn will enhance the organization's effectiveness. This will ultimately lead to an impactful and strong organization ready to cope with the challenges of today's turbulent times.

\section{References}

Arneson, j., Ruthwell, W.J., \& Naughton, J. (2013). ASTD Competency study: The training and development profession redefined, Alexandria, VA: ASTD.

Bernthal,P. R., Colteryahn, K., Davis, P., Naughton, j., Rothwell,W.J., \& Wellins, R. (2004). ASTD competency study: Mapping the future, new workplace learning and performance competencies, Alexandria, VA: ASTD.

Budhwar, P.S., \& Varma, A. (2011). Emerging HR management trends in India and the Way forward. Organizational Dynamics, 40(4), 317. https://doi.org/10.1016/j.orgdyn.2011.07.009

Guion, R. M. (1991). Personnel assessment, selection and placement. In M. D. Dunnette \& L. M. Hough (Eds.), Handbook of industrial and organizational psychology, Palo Alto, CA: Consulting Psychologists Press.

McClelland, D. (1973). Testing for competence rather than intelligence. American Psychologist, 28(1), 1-14. https://doi.org/10.1037/h0034092

McLagan, P. (1989). Models for HRD practice [4 volumes], Alexandria, VA: ASTD

McLagan, P., \& McCullough, R. (1983). Models for excellence: The conclusions and recommendations of the ASTD training and development competency study, Alexandria, VA: ASTD.

Pinto, P., \& Walker, J. (1978). A study of professional training and development roles and competencies. Madison, WI: ASTD.

Pio, E. (2007). HRM in Indian epistemologies: A review and avenues for future research. Human Resource Development Review, 17(3), 309-335. https://doi.org/10.1016/j.hrmr.2007.06.001

Piskurich, G.M., \& Sanders, E.S. (1998). ASTD models for learning technologies: Roles, competencies, and outputs. Alexandria, VA: ASTD.

Rao, T. V., \& Varghese, s. (2009). Trends and challenges of developing human capital in India. Human Resource Development International, 12(1), 15-34. https://doi.org/10.1080/13678860802638800

Rothwell, W. (1996). ASTD models for human performance improvement: Roles, competencies, and outputs, Alexandria, VA: ASTD.

Rothwell, W. (Ed.) (2000). ASTD models for human performance improvement (2d ed.), Alexandria, VA: ASTD. 
Rothwell, W.J., Sanders, E.S., \& Soper, J.G. (1999). ASTD models for workplace learning and performance: Roles, competencies, and outputs, Alexandria, VA: ASTD.

Spencer, L. M. Jr., \& Spencer, S.M. (1993). Competence at work: Models for superior performance, New York: Wily.

Srimannarayana, M. (2006). Training trends in India. Indian Journal of Training and Development, $X X X V I(2), 41-57$. 